\title{
GP management of community-acquired pneumonia in Italy: the ISOCAP study
}

\author{
C.M. Sanguinetti1, F. De Benedetto2, C.F. Donner3, \\ and the ISOCAP Study Group
}

ABSTRACT: GP management of community-acquired pneumonia in Italy: the ISOCAP study. C.M. Sanguinetti, F. De Benedetto, C.F. Donner, and the ISOCAP Study Group.

Background. Community-Acquired Pneumonia (CAP) is still a significant problem in terms of incidence, mortality rate, particularly in infants and the elderly, and socioeconomic burden. General Practitioners (GPs) are the first reference for patients with this disease, but there are few published studies regarding the outpatient treatment of CAP.

Methods. The ISOCAP study aimed to identify the type and outcome of the diagnostic-therapeutic management of CAP by GPs in Italy, within the framework of developing a closer interrelationship between GPs and pulmonary specialists. Thirty-six Pulmonary Divisions throughout Italy each contacted 5 local GPs who agreed to recruit the first 5 consecutive patients who consulted them for suspected CAP within the study's 1-year observation period.

Results. A total of 183 GPs took part in the study and enrolled, by the end of the observation period, 763 CAP patients; of these, complete data was available for 737 pa- tients $[$ males $=373$, females $=364$, mean age $( \pm$ SD) $58.8 \pm 19.6$ years]. $64.4 \%$ of patients had concomitant diseases, mainly systemic arterial hypertension and COPD. Diagnosis of CAP was based by GPs on physical examination only in $41.6 \%$ of cases; in the remaining chest $X$-ray was also performed. In only $4.6 \%$ of patients were samples sent for microbiological analysis. All patients were treated with antibiotics: $\mathbf{7 6 . 7 \%}$ in mono-therapy, $23.3 \%$ with a combination of antibiotics. The antibiotic class most prevalently used in mono-therapy was cephalosporin, primarily ceftriaxone; the most frequently used combinations were cephalosporin+macrolide and cephalosporin+quinolone. Mono-therapy was effective in $\mathbf{7 0 \%}$ of cases, the combination of two or more antibiotics in $91.2 \%$ of patients. Overall treatment efficacy was $\mathbf{9 4 . 7 \%}$; hospitalisation was required in $8.5 \%$ of cases.

Conclusions. Outpatient management of CAP by GPs in Italy is effective, hospitalisation being necessary only in the most severe cases due to age, co-morbidities or extent of pneumonia. This signifies a very significant savings in national health costs.

Monaldi Arch Chest Dis 2005; 63: 1, 23-29.

Keywords: Community-acquired pneumonia, general practitioner, pulmonary specialist, diagnosis, treatment, remission, hospitalisation.

1 U.O.C. di Pneumologia, Azienda Complesso Ospedaliero San Filippo Neri, Roma

2 U.O.C. di Pneumologia, Ospedale San Camillo De Lellis, Azienda Sanitaria di Chieti

3 Divisione di Pneumologia, Fondazione Salvatore Maugeri IRCCS, Centro Medico di Veruno (NO), Italy

Correspondence: Dr. Claudio M.Sanguinetti, U.O.C. di Pneumologia, A.C.O. San Filippo Neri, Via Martinotti 20, 00135 Roma, Italy; e-mail: csanguinetti@sanfilipponeri.roma.it

\section{Introduction}

General practitioners (GPs) are patients' first point of reference and in the front-line concerning the management of lower respiratory tract infections (LRTIs). Among LRTIs, community-acquired pneumonia (CAP) holds a very significant position; in USA it is responsible for 4 million new cases each year [1] and constitutes the sixth most common cause of death [2]. Up to $15 \%$ of patients require hospital admission because of severity of $\mathrm{CAP}$ and/or presence of risk factors, with annual global costs as high as four billion dollars [3]. The mortality of hospitalised patients reaches $13.6 \%$ and increases to $36.5 \%$ in those who need management in the intensive care unit [4].

Most subjects affected with pneumonia, especially those without risk factors, are treated at home, but not many studies concerning the diagnostic and therapeutic approach to CAP in the outpatient setting have been published [5-9].
The Italian Study in Outpatients affected with Community Acquired Pneumonia (ISOCAP) was undertaken to verify and extend the little available data on GP behaviour in Italy regarding CAP, in order to enhance GPs' professional competence and to promote closer interrelationships between GPs and pulmonary specialists.

The aim of the present study was to evaluate the diagnostic workup that Italian GPs adopt in patients affected with CAP, and the efficacy and tolerability of the antibiotic therapy they prescribe in such patients.

\section{Methods}

\section{Study design}

This observational trial was carried out between 1 January 1999 and 15 May 2001. 36 Divisions of Pulmonary Disease distributed throughout Italy, following the approval of their local Ethical Committee, each selected 5 GPs who agreed in 
turn to recruit 5 consecutive patients who consulted them for suspected CAP. The Pulmonary Divisions acted also as a reference for the GPs. Thus $180 \mathrm{GPs}$ and some $800 \mathrm{CAP}$ patients were expected to be enrolled for the study.

Upon completion of the survey, 183 GPs participated in the study, and 763 cases of CAP were collected, 737 of which were valid for analysis (92.1\% of the expected) in that they fulfilled inclusion/exclusion criteria and data were complete.

\section{Questionnaire for the GPs}

GPs participating in the study had to fill in a questionnaire aimed at defining the personal characteristics of each GP. The questionnaire included the age of the GP, how long he had been practising as a physician in the national health system, the number of patients he had under his care, the site (urban or rural) of work.

The GPs were also given a form to record each patient's data concerning private and clinical data, including comorbidities diagnostic examinations, the reasons for outpatient treatment of CAP in that patient, therapeutical prescriptions, length of treatment, and outcome.

Mean age (+SD) of GPs was $47 \pm 4.7$ years, and they had been practising general medicine for $16 \pm 6.8$ years on average. The total number of patients referring to the 183 GPs was 233,316 , with a mean number of 1,363 patients per GP. The mean number of patients older than 65 years was 342 (i.e. $24.8 \%$ of the total patient population of the study). The majority of GPs (88.4\%) worked close to the hospital (within a distance of $10 \mathrm{~km}$ ). The GP decided to treat a patient with suspected CAP at home or not on the basis of feasibility of domiciliary treatment in each case.

\section{Definition of outcome variables}

Remission ('success') was defined as the disappearance of clinical symptoms at physical examination with or without negativisation of the radiological picture.

In the case of non resolution with the initial empirical antibiotic treatment, the options were recourse to other antibiotic treatment or hospitalisation in the case of ineffective treatment or the need for further diagnostic investigation.

\section{Inclusion/exclusion criteria}

For inclusion in the study patients, of either sex, had to be 18 years or older and to present signs of CAP as defined by fever, localised rales and/or signs of consolidation at physical examination, according to international guidelines for CAP $[2,10]$. Patients were excluded if they had been admitted to hospital in the two weeks preceding diagnosis of CAP, or were affected with an immunodepressive condition.

\section{Statistical Analysis}

As this was an observational trial statistical analyses were of a descriptive type: frequencies and rates for discrete variables; mean, median, standard deviations and ranges for continuous variables.

Analysis was first performed on the sample as a whole, then separately for patients who underwent vs. did not undergo chest X-ray: this subdivision allowed us to check whether X-ray modified in some way the GPs' management of CAP.

Analyses evaluating the impact of several risk factors were also performed.

\section{Results}

\section{Patient characteristics}

The results presented here refer to all evaluable patients $(n=737)$ irrespective of whether they had radiological or only clinical diagnosis of CAP. Comparison of the two subgroups of patients (with and without chest X-ray) did not evidence any difference in terms of either risk factors or diagnostic-therapeutic management.

There were 373 males and 364 females, mean $(+\mathrm{SD})$ age $58.8 \pm 19.6$ years. Current smokers were $26.6 \%$. $84.7 \%$ of patients did not consume alcoholic beverages, and $8.8 \%$ were exposed to an occupational risk (table 1).

The majority of patients $(64.4 \%)$ reported concomitant chronic diseases, among which systemic arterial hypertension and chronic obstructive pulmonary disease (COPD) were prevalent. About half $(52 \%)$ of the patients with co-morbidities presented more than one concurrent illness (table 2).

\begin{tabular}{|c|c|c|}
\hline & Number of patients & $\%$ \\
\hline \multicolumn{3}{|l|}{ SEX } \\
\hline Males & 374 & 50.7 \\
\hline Females & 363 & 49.3 \\
\hline \multicolumn{3}{|l|}{ AGE (years) } \\
\hline Mean & 58.8 & \\
\hline Median & 62.0 & \\
\hline Minimum & 18.0 & \\
\hline Maximum & 104.0 & \\
\hline \multicolumn{3}{|l|}{ SMOKING HABIT } \\
\hline Active smokers & 196 & 26.6 \\
\hline $\begin{array}{l}\text { Ex smokers } \\
\text { (since at least } 6 \text { months) }\end{array}$ & 111 & 15.1 \\
\hline Non smokers & 410 & 55.7 \\
\hline No data available & 20 & 2.6 \\
\hline \multicolumn{3}{|l|}{ ALCOHOL CONSUMPTION } \\
\hline No & 624 & 84.7 \\
\hline Yes & 113 & 15.3 \\
\hline \multicolumn{3}{|l|}{ OCCUPATIONAL RISK } \\
\hline No & 672 & 91.2 \\
\hline Yes & 65 & 8.8 \\
\hline
\end{tabular}


Table 2. - Co-morbidities in CAP study patients $(n=737)$

\begin{tabular}{|c|c|c|}
\hline Numb & er of patients & $\%$ \\
\hline \multicolumn{3}{|c|}{ PRESENCE OF CO-MORBIDITIES } \\
\hline Yes & 475 & 64.5 \\
\hline No & 262 & 35.5 \\
\hline \multicolumn{3}{|c|}{ NUMBER OF CO-MORBIDITIES PER PATIENT } \\
\hline One & 229 & 48.2 \\
\hline Two & 144 & 30.3 \\
\hline Three & 66 & 13.8 \\
\hline Four & 28 & 6.0 \\
\hline Five & 5 & 1.0 \\
\hline Six & 3 & 0.6 \\
\hline \multicolumn{3}{|l|}{ TYPE OF CO-MORBIDITY * } \\
\hline Systemic arterial hypertension & 245 & 32.8 \\
\hline COPD & 166 & 22.2 \\
\hline Diabetes & 92 & 12.3 \\
\hline Ischemic heart disease & 81 & 10.8 \\
\hline Vascular disease & 61 & 8.1 \\
\hline Congestive heart failure & 55 & 7.3 \\
\hline Liver complaint & 22 & 2.9 \\
\hline Kidney failure & 9 & 1.2 \\
\hline
\end{tabular}

Table 3. - Findings at physical examination, with or without associated chest X-ray, on which the GP based diagnosis of CAP

\begin{tabular}{lcc}
\hline $\begin{array}{l}\text { Findings at physical } \\
\text { examination }\end{array}$ & $\mathbf{N}^{\circ}$ patients & \% \\
\hline $\begin{array}{l}\text { Localised rales + chest X-ray } \\
\text { Localised rales }\end{array}$ & 287 & 38.9 \\
$\begin{array}{l}\text { Chest X-ray } \\
\text { Localised rales + signs } \\
\text { of consolidation in lung } \\
+ \text { chest X-ray }\end{array}$ & 57 & 31.1 \\
$\begin{array}{l}\text { Localised rales + signs } \\
\text { of consolidation in lung }\end{array}$ & 57 & 7.7 \\
$\begin{array}{l}\text { Signs of consolidation in lung } \\
\text { Signs of consolidation in lung } \\
+ \text { chest X-ray }\end{array}$ & 18 & 7.7 \\
Not specified & 30 & 7.2 \\
\hline TOTAL & 6 & 4.1 \\
\hline
\end{tabular}

\section{Basal diagnostic procedures}

The diagnosis of CAP was based by the GP only on clinical signs at the physical examination in $41.6 \%$ of cases and the prevalent finding was presence of localized rales, alone (31.1\%) or associated with signs of consolidation (7.2\%) (table 3). Chest $\mathrm{x}$-ray was requested by GPs to confirm the clinical diagnosis of CAP in 431/737 cases (58.4\%), but the diagnostic modality (chest radiography or not) does not seem to have influenced the outcome (table 4).

In only $4.6 \%$ of patients was an etiological diagnosis of CAP attempted by sending a sputum test or blood sample to a laboratory for microbiological analysis (table 5).

It is probable that the lack of availability of a reliable microbiological laboratory within close proximity often discourages the physician in this regard. In any case, international guidelines (ATS, BTS, EORTC) [10-12] do not recommend the use of microbiological examinations in outpatient management.

\section{Total diagnostic procedures}

Diagnostic procedures (blood and serological analyses and X-ray) were prescribed by GPs on average 1.65 times per patient: in particular 1.45 for blood gases analysis, 1.41 for serology and 1.75 for X-rays.

\section{Antibiotic Therapy}

All patients with CAP were treated with antibiotic therapy, $565(76.7 \%)$ with one antimicrobial drug only, $172(23.3 \%)$ with a combination of different antibiotics.

\section{A) TREATMENT WITH ONE ANTIBIOTIC ONLY}

The prevalent class of drugs used was cephalosporin, accounting for $42.4 \%$ of prescriptions, followed by quinolones (24.6\%), macrolides (17.8\%), penicillins (14.3\%) and others $(0.7 \%)$ (table 6). Cephalosporins, mainly ceftriaxone, prescribed in about $22 \%$ of all patients, were the preferred choice particularly for elderly patients ( $>65$ years) and those with co-morbidities (table 7).

The preferred mode of administration for patients $\leq 65$ years without co-morbidities was oral,

Table 4. - Outcome of CAP in relation to performance or not of chest X-ray

\begin{tabular}{|c|c|c|c|c|c|c|}
\hline \multirow[t]{3}{*}{ Chest X-ray } & \multirow{2}{*}{\multicolumn{2}{|c|}{ Whole sample }} & \multicolumn{4}{|c|}{ OUTCOME } \\
\hline & & & \multicolumn{2}{|c|}{ Success } & \multicolumn{2}{|c|}{ Failure } \\
\hline & No. & $\%$ & No. & $\%$ & No. & $\%$ \\
\hline NO & 306 & 41.6 & 225 & 73.5 & 81 & 26.4 \\
\hline YES & 431 & 58.4 & 328 & 76.1 & 103 & 23.8 \\
\hline TOTAL & 737 & 100 & 553 & 75.0 & 184 & 25.0 \\
\hline
\end{tabular}




\begin{tabular}{|c|c|c|}
\hline & $\mathbf{N}^{\circ}$ & $\%$ \\
\hline $\begin{array}{l}\text { Patients in whom } \\
\text { a microbiological } \\
\text { analysis was requested }\end{array}$ & $34 / 737$ & 4.6 \\
\hline \multicolumn{3}{|l|}{ Type of tests requested* } \\
\hline $\begin{array}{l}\text { Haemoculture } \\
\text { Sputum test } \\
\text { Serology }\end{array}$ & $\begin{array}{c}1 \\
18 \\
22\end{array}$ & $\begin{array}{c}2.4 \\
43.9 \\
53.7\end{array}$ \\
\hline TOTAL & 41 & 100 \\
\hline
\end{tabular}

* More than one test requested in individual patients.

Table 6. - Antibiotics prescribed in mono-therapy in 565 cases of CAP treated in the community

\begin{tabular}{lcc}
\hline Antibiotic class & $\mathbf{N}^{\circ}$ patients & \% \\
\hline Cephalosporin & 240 & 42.4 \\
Quinolone & 139 & 24.6 \\
Macrolide & 101 & 17.8 \\
Penicillin & 81 & 14.3 \\
Other & 4 & 0.7 \\
\hline TOTAL & $\mathbf{5 6 5}$ & $\mathbf{1 0 0}$ \\
\hline
\end{tabular}

whereas patients $>65$ years and with co-morbidities were mostly treated parenterally: physicians chose the parenteral administration of the antibiotic when the severity of the pneumonia required a rapid concentration of the antibiotic at the infection's site to obtain better therapeutical results.

The median treatment duration was 10 days, decreasing to 8 days when an intravenous drug was used (table 8).

Mono-therapy showed a $70 \%$ efficacy; the rate of hospitalisation was $9.2 \%$, rising to $14.3 \%$ in patients > 65 years of age and with co-morbidities; one only death occurred in the study population during the period of observation.In $6 \%$ of cases a further drug was added, this being a quinolone, macrolide or cephalosporin. The initial antibiotic was substituted on account of ineffectiveness in $6.4 \%$ of cases.

The efficacy in the at-risk subgroup of patients (>65 years and with co-morbidities) was $65.7 \%$, which reached $73.6 \%$ with ceftriaxone (table 9).

\section{B) TREATMENT WITH TWO OR MORE ANTIBIOTICS}

A combination of antibiotics was used from the outset in about one-fourth of patients (23.3\%); in half of these this consisted of a cephalosporin plus macrolide for 10 days. The other combination largely used was that of a cephalosporin plus quinolone. Globally combination therapy achieved

Table 7. - Top 10 antibiotics most frequently utilised as mono-therapy in community-treated CAP and type of patient $(n=565)$

\begin{tabular}{|c|c|c|c|c|c|c|c|c|c|c|}
\hline \multirow[b]{5}{*}{ DRUG } & & & \multicolumn{8}{|c|}{ AGE CLASS } \\
\hline & & & \multicolumn{4}{|c|}{$\leq 65 \mathrm{yrs}$} & \multicolumn{4}{|c|}{$>65 \mathrm{yrs}$} \\
\hline & & & \multicolumn{4}{|c|}{ Comorbidity } & \multicolumn{4}{|c|}{ Co-morbidity } \\
\hline & \multicolumn{2}{|c|}{ TOTAL } & \multicolumn{2}{|c|}{ NO } & \multicolumn{2}{|c|}{ YES } & \multicolumn{2}{|c|}{ NO } & \multicolumn{2}{|c|}{ YES } \\
\hline & $\mathbf{N}^{\circ}$ & $\%$ & $\mathbf{N}^{\circ}$ & $\%$ & $\mathbf{N}^{\circ}$ & $\%$ & $\mathbf{N}^{\circ}$ & $\%$ & $\mathbf{N}^{\circ}$ & $\%$ \\
\hline Ceftriaxone & 104 & 21.8 & 24 & 23.0 & 20 & 19.2 & 7 & 6.7 & 53 & 50.9 \\
\hline Clarithromycin & 89 & 18.6 & 49 & 55.0 & 21 & 23.5 & 2 & 2.2 & 17 & 19.1 \\
\hline Levofloxacin & 71 & 14.8 & 23 & 32.3 & 16 & 22.5 & 4 & 5.6 & 28 & 39.4 \\
\hline Amoxi/clavul & 46 & 9.6 & 19 & 41.3 & 13 & 28.2 & - & - & 14 & 30.4 \\
\hline Ciprofloxacin & 37 & 7.7 & 9 & 24.3 & 11 & 29.7 & 2 & 5.4 & 15 & 40.5 \\
\hline Cefonicid & 34 & 7.1 & 6 & 17.6 & 6 & 17.6 & - & - & 22 & 64.7 \\
\hline Ceftazidime & 29 & 6.0 & 6 & 20.6 & 5 & 17.2 & 1 & 3.4 & 17 & 58.6 \\
\hline Moxifloxacin & 27 & 5.6 & 5 & 18.5 & 13 & 48.1 & - & - & 9 & 33.3 \\
\hline Cefodizime & 22 & 4.6 & 2 & 9.0 & 4 & 18.1 & 1 & 4.5 & 15 & 68.1 \\
\hline Cefotaxime & 18 & 3.7 & 4 & 22.2 & 7 & 38.8 & - & - & 7 & 38.8 \\
\hline
\end{tabular}

Table 8. - Length of treatment (days) of antibiotic mono-therapy for CAP in relation to the type of drug used

\begin{tabular}{lcccc}
\hline & TOTAL & Ceftriaxone & Clarithromycin & Levofloxacin \\
\hline MEAN & 9.09 & 8.59 & 10.26 & 9.96 \\
MEDIAN & 10.00 & 8.00 & 10.00 & 10.00 \\
s.d. & 3.23 & 3.20 & 3.49 & 3.79 \\
MIN & 1.00 & 1.00 & 3.00 & 1.00 \\
\hline MAX & $\mathbf{2 5}$ & $\mathbf{2 5}$ & $\mathbf{2 1}$ & $\mathbf{2 3}$ \\
\hline
\end{tabular}


Table 9. - Results of community-treatment of CAP with antibiotic mono-therapy

\begin{tabular}{|c|c|c|c|c|c|c|c|c|c|}
\hline \multicolumn{2}{|c|}{ TOTAL } & \multicolumn{2}{|c|}{ Remission } & \multicolumn{2}{|c|}{ Other form of therapy } & \multicolumn{2}{|c|}{ Hospitalisation } & \multicolumn{2}{|c|}{ Death } \\
\hline $\mathbf{N}$ & $\%$ & $\mathbf{N}$ & $\%$ & $\mathbf{N}$ & $\%$ & $\mathbf{N}$ & $\%$ & $\mathbf{N}$ & $\%$ \\
\hline \multicolumn{10}{|c|}{ Whole sample } \\
\hline 565 & 100 & 396 & 70.0 & 116 & 20.5 & 52 & 9.2 & 1 & 0.1 \\
\hline \multicolumn{10}{|c|}{ Patients $>65$ yrs and with co-morbidities } \\
\hline 181 & 32.0 & 119 & 65.7 & 35 & 19.3 & 26 & 14.3 & 1 & 0.5 \\
\hline
\end{tabular}

Table 10. - Efficacy of combination antibiotic therapy in outpatient management of CAP $\left(n^{\circ}\right.$ cases $\left.=172\right)$

\begin{tabular}{lccccccc}
\hline Combination of antibiotics & \multicolumn{2}{c}{ Remission } & \multicolumn{2}{c}{ Other form of therapy } & \multicolumn{2}{c}{ Hospitalisation } & \multicolumn{2}{c}{ TOTAL } \\
& N. & $\mathbf{\%}$ & N. & $\mathbf{\%}$ & N. & \% & N. \\
\hline Cephalosporin + Macrolide & 84 & 95.4 & 2 & 2.3 & 2 & 2.3 & 88 \\
Cephalosporin + Quinolone & 34 & 87.1 & 4 & 10.2 & 1 & 2.5 & 39 \\
Other combinations & 39 & 86.7 & 4 & 8.9 & 2 & 4.4 & 45 \\
\hline TOTAL & $\mathbf{1 5 7}$ & $\mathbf{9 1 . 3}$ & $\mathbf{1 0}$ & $\mathbf{5 . 8}$ & $\mathbf{5}$ & $\mathbf{2 . 9}$ & $\mathbf{1 7 2}$ \\
\hline
\end{tabular}

Table 11. - Length of treatment (days) of CAP in relation to type of combination of antibiotics ( $n^{\circ}$ patients $=172$ )

\begin{tabular}{lccc}
\hline & TOTAL & $\begin{array}{c}\text { Cephalosporin+ } \\
\text { Macrolide }\end{array}$ & $\begin{array}{c}\text { Cephalosporin+ } \\
\text { Quinolone }\end{array}$ \\
\hline MEAN & $\mathbf{1 0 . 2 8}$ & $\mathbf{1 0 . 3 0}$ & $\mathbf{1 0 . 5 2}$ \\
MEDIAN & 10.00 & 10.00 & 10.00 \\
s.d. & 3.00 & 2.59 & 2.84 \\
MIN & 3.00 & 6.00 & 6.00 \\
MAX & 20 & 18 & 20 \\
\hline
\end{tabular}

an efficacy of $91.2 \%$; that of cephalosporin plus macrolide had a $95.4 \%$ efficacy (table 10). The mean duration of combination therapy was 10.28 days (table 11).

\section{Global effectiveness}

The global effectiveness of the therapeutic approach, including the adding of another drug or substitution of the first one, was $94.7 \%$ with a rate of hospitalisation of $8.5 \%$, due in most cases to a worsening of the clinical picture.

\section{Tolerability}

The drugs used in this trial did not cause any adverse drug reaction in $95.7 \%$ of patients. No serious adverse event occurred and in only $5 / 32$ patients was there a need to substitute therapy. Pain at the Achilles tendon was reported by one patient treated with a quinolone.

\section{Duration of disease}

The mean duration of the infective episode was 15 days.

\section{Discussion}

In Italy CAP accounts for $1.35 \%$ of global death causes and over $21 \%$ of the respiratory ones, with a mortality rate of 13 per hundred thousand inhabitants, that increases to about 200 in the elderly [13]. However, few studies have dealt with the outpatient management of CAP by GPs and the most recent published European data [5] on the diagnostic-therapeutic management of CAP, including Italian data, refer to the year 1996.

A European study (ESOCAP) on GPs' behaviour regarding the decision to hospitalise patients with CAP [6] already showed that this decision was mainly based on clinical signs indicating severe CAP. Furthermore, important diversities of behaviour among the different European countries emerged. The same was eventually confirmed in the study carried out by Huchon et al. [5], which showed a uniform rate of recourse to complementary investigations and hospitalisation, $17 \%$ and $19 \%$ respectively, on the part of GPs in the case of suspicion of CAP, but not the same homogeneity concerning antibiotic prescription. In fact, Italian GPs almost always prescribe antibiotics (97\%) but British (84\%) and German (77\%) GPs do so much less frequently. Even more striking was the difference found between countries concerning recourse to the intravenous mode of antibiotic administration in CAP: $71 \%$ in Italy compared to $0-17 \%$ in other European countries [5].

Similar inter-country differences emerged regarding frequency of chest X-ray, sputum tests and other diagnostic tools in the suspicion of CAP [7].

These differences may be significant because CAP accounts for a consistent proportion of health costs, especially in terms of rate of hospital referral and inappropriate antimicrobial therapy even in the presence of simple upper respiratory tract infections [14], which can only have the effect of enhancing bacterial resistance to antibiotics. 
The ISOCAP trial, in terms of the number of participating GPs $(n=183)$ distributed throughout the whole national territory and the large patient sample size $(n=737)$, represents a significant data font. A further positive aspect of this study is its attempt to improve the collaboration between the hospital centres (pulmonary specialists) and GPs for the purposes of a shared management of CAP both in the outpatient setting and, where necessary, in hospital.

The sample studied was recruited by GPs in their daily professional practice and is thus adequately representative of the general population, not subject to the limit of a pre-selection such as when data is collected in hospital inpatients who, by virtue of being hospitalised, are not completely representative of the general population but constitute a group of subjects characterised by more severe disease.

However, even in the general population studied here we found a high incidence of chronic diseases such as COPD and systemic arterial hypertension, sometimes mutually coexisting and also combined with other medical conditions in more than one patient affected by pneumonia. Besides testifying to their wide diffusion in the context of the Italian population, these co-morbidities represent, as demonstrated in many studies [11, 12, 1517], a high risk factor in terms of mortality, particularly if associated with old age; in this case the occurrence of pneumonia thus constitutes the pathological expression of a worse prognosis which it is often advisable to treat in hospital.

Even if from the present study it emerged that almost $60 \%$ of GPs used x-ray to confirm diagnosis in suspected pneumonia, the fact remains of the potential difficulty of access to radiology units. In fact, in more than $40 \%$ of cases GPs based the diagnosis, at least in the first instance, only on symptoms reported by the patient and on significant signs at the physical examination. An improved collaboration between GPs and hospital-based and local health services will certainly facilitate the performance of routine X-rays also in outpatients. Chest X-ray is important not only to confirm diagnosis but also to delineate the extent and morphologic features of the pneumonia; it can indicate, together with the patient's characteristics, the probability of a given etiology, and it can also enable a prognostic evaluation, since the impairment of more lobes of the same lung and/or the bilateral nature of the infection represent important factors of severity of CAP.

It appears even more difficult to probe in nonhospitalised patients the etiology of CAP through microbiological and blood examinations. In fact in this study only $4.6 \%$ of GPs requested diagnostic investigations of this type. However, aside from the difficulty in the outpatient setting of collecting and delivering to the laboratory reliable samples of bronchial or blood secretions for microbiological and blood analyses, the physician who has in front of him a patient, whether at home or in his surgery, affected by CAP must intervene rapidly with an effective antibiotic therapy and cannot wait for at least 3 days or more for the laboratory to respond to the microbiological question. This, over and above the fact that in more than half of cases no pathogen is isolated at all, not even in the most highly specialised laboratories, signifies that therapy must of necessity be empirical. Hence it is very important to evaluate carefully the conditions of the patient and have at least a minimum knowledge of the local epidemiology and of the panorama of resistances of the various infective agents to antibiotics, as is recommended in the guidelines for pneumonia [10-12], in order to be able to prescribe a useful anti-infective treatment.

According to findings from the ISOCAP study, in three-quarters of cases the antibiotic is administered as mono-therapy and cephalosporins, especially $3^{\text {rd }}$ generation, are the most commonly used. In fact GPs place wide trust in this class of drug, well known for its efficacy and tolerability, and which in many cases avoids the need for hospitalisation. In the present survey the analysis of the antibiotics most frequently used in mono-therapy for the treatment of CAP shows that ceftriaxone is the most used in outpatients affected by CAP in Italy, followed by clarithromycin, levofloxacin, amoxiclav, and other cephalosporins. More than half of the cases in which cephalosporins were used, however, were situations of greater severity, i.e. advanced age and presence of co-morbidities.

Parenteral administration of antibiotics at home has attracted much interest in the last few years, especially in anglo-saxon health systems where, in the past, such practice never existed outside of the hospital setting. This has led to the setting up of services for the administration at home or in outpatient clinics of such therapy, known as Outpatient Parenteral Antibiotic Therapy (OPAT). The costs due to hospitalisation can thus be avoided and at the same time the quality of life of the patient is improved, in particular in the case of infants or the elderly, who can remain in their own family environment and avoid the stress to which they would be inevitably subject in the case of hospitalisation [18]. Parenteral administration in the outpatient setting has been usual practice for many years in our country and is satisfactorily carried out by GPs and by the patients themselves, who often expressly request such a mode of treatment to enhance rapidly the good outcome of the disease. We can only speculate whether the Italian practice of treating CAP outpatients with parenteral administration of cephalosporins or protected penicillins could somehow have addressed the favourable outcome of many infections, including pneumonia, and possibly contributed to the low incidence of high-level resistance of S.pneumoniae to penicillin, that are features characterising our country in comparison to others [19].

In conclusion, from an overall look at the ISOCAP data it may be affirmed that Italian GPs are correctly managing CAP: the effectiveness of their therapeutic approach in the overwhelming majority of patients (94.7\% global efficacy) and the diagnostic-therapeutic workup adopted (which represent a translation of international guideline recommendations into the local context) are reflected without doubt in savings in health and social services costs, especially in relation to the low percentage of patients who need to be admitted to hospital, which is the most heavy burden from all points of view. 


\section{References}

1. Centers for Disease Control and Prevention. Premature deaths, monthly mortality and monthly physicians contacts-United States. MMWR Morb Mortal Wkly Rep 1997; 46: 556.

2. Bartlett JG, Dowell SF, Mandell LA, File TM, Jr, Musher DM, Fine MJ. Practice Guidelines for the management of community-acquired pneumonia in adults. Guidelines from the IDSA. Clin Infect Dis 2000; 31: 347-382.

3. Medicare and Medicaid statistical supplement 1997. Health Care Finance Rev 1997; 18S: 73.

4. Fine MJ, Smith MA, Carson CA et al. Prognosis and outcomes of patients with community-acquired aneumonia. A Meta-analysis. JAMA 1995; 274: 134-141.

5. Huchon GJ, Gialdroni-Grassi G, Léophonte P, Manresa F, Schaberg T, Woodhead M. Initial antibiotic therapy for lower respiratory tract infection in the community: a European survey. Eur Respir J 1996; 9: 1590-1595.

6. Shaberg T, Gialdroni-Grassi G, Huchon G, Léophonte P, Manresa F, Woodhead M, for the European Study Group of Community-Acquired Pneumonia (ESOCAP) of ERS. Thorax 1996; 51: 1017-1022.

7. Woodhead M, Gialdroni-Grassi G, Huchon GJ, Léophonte P, Manresa F, Schaberg T. Use of investigations in lower respiratory tract infection in the community: a European survey. Eur Respir J 1996; 9: 1596-1600.

8. Laurichesse H, Robin F, Gerrbaud L, Pochet P, Gourdon $\mathrm{F}$ et al. Empirical therapy for non-hospitalized patients with community-acquired pneumonia. Eur Respir $J$ 1998; 11: 73-78.

9. Fantin B, Aubert JP, Unger P, Lecoeur H, Carbon C. Clinical evaluation of the management of communityacquired pneumonia by general practitioners in France. Chest 2001; 120: 185-192.

10. American Thoracic Society. Guidelines for the management of adults with community-acquired pneumonia - Diagnosis, assessment of severity, antimicrobial therapy, and prevention. Am J Respir Crit Care Med 2001, 163, 1730-54.

11. British Thoracic Society. Guidelines for the management of community acquired pneumonia in adults. Thorax 2001, 56 (suppl. IV); 1-64.

12. ESOCAP Committee. ERS Task Force Report - Guidelines for management of adult community-acquired lower respiratory tract infections. Eur Respir J 1998, 11, 986-91.

13. De Benedetto F, D'Intino A. Polmoniti Comunitarie. In: Donner CF \& Sanguinetti CM Eds. Trattato Italiano di Pneumologia. Ediaipo Scientifica, Pisa 2000: 791-820.

14. Arrol B, Goodyear-Smith F. General practitioner management of upper respiratory tract infections: when are antibiotics prescribed? New Zeal Med J 2000; 113: 493-496.

15. Hedlund J, Kalin M, Ortqvist A. Recurrence of pneumonia in middle-aged and elderly adults after hospitaltreated pneumonia: aetiology and predisposing conditions. Scand J Infect Dis 1997; 29: 387-392.

16. Fine MJ, Hanusa BH, Lave JR et al. Comparison of a disease-specific and a generic severity of illness measure for patients with community acquired pneumonia. J Gen Intern Med 1995; 10: 359-368.

17. Fine MJ, Auble TE, Yealy DM et al. A prediction rule to identify low-risk patients with community-acquired pneumonia. N Engl J Med 1997; 336: 243-250.

18. Marie TJ, Durant H, Yates L. Community-acquired pneumonia requiring hospitalization: 5-year prospective study. Rev Infect Dis 1989; 11: 586-599.

19. Marchese A, Fadda G, Nicoletti G, Schito GC. Prevalence of antimicrobial resistance in bacterial pathogens causing lower respiratory tract infections: results of the PROTEKT Italy Survey. 43 ${ }^{\text {rd }}$ Interscience Conf. on Antimicrobial Agents and Chemotherapy. ASM, Chicago, USA, September 2003.

\section{ISOCAP STUDY}

Board members: De Benedetto Fernando, Chieti; Del Prato Bruno, Napoli; Donner Claudio F., Veruno (Novara); Fogliani Vincenzo, Milazzo (Messina); Logroscino Carlo, Bari; Mistretta Antonino,Catania; Sanguinetti Claudio, Roma; Schito Giancarlo, Genova.

ISOCAP reference centers: Cacciani Giancarlo - Az. Osp. di Parma (Parma); Canonica G. Walter - Clinica App. Resp., Univ. di Genova (GE); Dolcetti Alessandro - Osp. S. L. Gonzaga, Orbassano (TO); Donner Claudio - Fondazione Salvatore Maugeri, Veruno (NO), Falcone Franco - Ospedale Bellaria (BO), Lo Cicero Salvatore - Ospedale Niguarda (MI), Neri Margherita - Fondazione Salvatore Maugeri, Tradate (VA); Pozzi Ernesto - Ospedale S. Luigi Gonzaga, Orbassano (TO); Schiavina Mario - Ospedale S. Orsola (BO), De Benedetto Fernando - Ospedale S. Camilillo de Lellis $(\mathrm{CH})$, Munafò Giuseppe - Ospedale S. Maria Goretti (LT), Parentini Giancarlo - Ospedale Civile di S.Antonio Abate, Fivizzano (MS), Penza Oronzo - Az. Ospedaliera Silvestrini, S.Andrea delle Fratte (PG); Principe Rosa Stella - Ospedale C. Forlanini USL RM/10 (Roma); Sanguinetti Claudio M - Complesso Ospedaliero San Filippo Neri (ROMA), Saltini Cesare IRCCS Spallanzani - Roma, Tubaldi Alberto Ospedale di Macerata, Agati Gesualdo - Ospedale E. Morelli (Reggio Calabria); Crimi Nunzio - Ospedale Tommaselli (CT); Del Prato Bruno Ospedale Cardarelli (NA) I; Ferrara Giuseppe - Azienda Ospedaliera Cervello (PA); Fogliani Vincenzo - Ospedale di Milazzo(ME); De Francesca Francesco - A.O. Pugliese Ciaccio (CT); Lsedda Marcello - Ospedale Binaghi (CA); Logroscino Carlo - Fondazione Salvatore Maugeri, Cassano Murge (BA); Mirabella Saverio - Ospedale Clinicizzato "Ascoli - Tommaselli" (CT); Moretti Annamaria - Ospedale S. Paolo (BA); Picciolo Fortunato - Ospedale Piemonte (ME); Viola Benedetto - Ospedale A. Rizza (SC); Parola Daniela - Ospedale Cartoni Az. USL Roma, Rocca Priora(ROMA); Zanello Angelo Presidio Ospedaliero di Aosta (AO).

Participating GPs: Del Canale Stefano, Cavatorti Paolo, Elgorni Basevi Paolo, Barazzoni Giovanni, Bertini Augusto, Fonzi Stefano, Brasesco Pierclaudio, Mantovani Giuseppe, Ceratto Ernestina, Cerchia Luigi, D'Alessandro Davide, Giacoletti Alessandro, Canal Maurizio, Gioria Massimo, Usurini Franco, Rossi Ezio, Empiri Silvio, Torbioni Guglielmo, Infusini Antonio Ernesto, Biavati Francesco, Zoccoli Giuseppe, Valentini Giulio, Zanna Marcello, Cavalieri Ivan, Colmegna Angela, Beati Fulvio, Bertelli Francesco, Calzolari Mauro, Manaretto Fulvio, De Prati Attilio, Rolfo Alberto, Zanna Marcello, Parente Giuseppe, Flammini Miranda, Fantinelli Sauro, D’Emilio Agostino Moreno, D'Iorio Bruno, Ianiro Gabriella, Ferrara Diego Pietro, D’Uva Mario, Le Foche Luca, Nardacci Giuseppe, Mangullo Angelo, Testa Ubaldo, Vatteroni Mario, Galli Giuseppe, Parenti Gianni Germini Fabrizio, Berardi Mario, Rossi Francesco, Coppini Bruno, Cecchi Paolo, Zamperini Daniele, Ricciardi Maria Maddalena, Rodi Vittorio, Castellano Paolo, Belfiori Mauro, Sampaolo Guido, Araco Mario, Raimondo Benedetto, Grimaldi Orazio Umberto, Tamburrini Gino, Avio Mariano, Angerilli Francesco, Mari Romano, Cannelli Bernardo, Toscano Emanuele, Agostino Giuseppe, Gambino Fortunato, Imbalzano Pasquale, Pontari Antonino, Calvo Salvatore, Vagliasindi Giovanni, Testa Carlo, Altieri Vincenzo, Spezzano Linda, Alano Raffaele, De Simone Beniamino, Costigliola Franco, Napoli Luigi, Bennici Alessandro, Nicolosi Gioacchino, Simonetti Giuseppe, La Milia Salvatore, Trio Francesco, Nicosia Giovanni, Fazio Giuseppe, Di Geronimo Luciana, Materia Salvatore, Russo Vincenzo, Foresta Antonio, Guerra Antonio, Gerace Antonio, Paracchini Giuseppe, Fadda Fernando, Frau Marino, Montis Gianpiero, Albertoni Silvana, Campanelli Anna Pia, Santoro Mariangela, Mirizzi Giovanni, Lassandro Michele, Italia Sebastiano, Romano Sebastiano, Giorgianni Paolo, De Mola Cosimo, Spezzacatena Francesco, Ruttigliano Vincenza, Lampugnani Francesco, Stufano Nicola, Armeli Gustavo, Ferrara Salvatore, Cannuni Pietro, Alibrando Antonino, Costa Annamaria, Bosco Vincenzo, Claudio Sergio, Colomasi Giuseppe, Quadarella Carmelo, Del Vecchio Gianfranco, Riccardi Stefano, Bevilacqua Marcantonio, Pirozzi Giuseppe, Scipioni Andrea, Pomati Carlo, Sterrantino Fortunato, Bessolo Luciano, Magliano Aldo. 